\title{
DESOBEDIÊNCIA CIVIL AO PODER SOBERANO EM LA BOÉTIE
}

\author{
FELIPE AUGUSTO FERREIRA FEIJÃO ${ }^{1}$
}

RESUMO: Este texto procura expor a noção de recusa ao serviço de um poder soberano presente no Discurso da servidão voluntária, 1577, de Étienne de La Boétie. Para tanto, uma breve análise da obra será proposta do ponto de vista de ser uma inovação para o tempo em que é pensada e escrita e de, sobretudo formar um conjunto de resistência ao poder que se manifesta estabelecido e institucionalizado como natural.

PALAVRAS-CHAVE: Desobediência; Poder; Soberano.

\begin{abstract}
This text seeks to expose the notion of refusal in the service of a sovereign power present in Étienne de La Boétie's Discourse on Voluntary Servitude. To do so, a brief analysis of the work will be proposed from the point of view of being an innovation for the time in which it is thought and written and, above all, to form a set of resistance to power that manifests itself established and institutionalized as natural.
\end{abstract}

KEYWORDS: Disobedience; Power; Sovereign.

O pensamento de Étienne de La Boétie é expressão de uma verdadeira inovação, uma vez que emerge num contexto bastante diverso do que passará a propor. Em primeiro lugar, faz bem observar que até então a filosofia era sinônimo de obras positivadas em tratados, ou seja, em defesa da verdade do que era colocado como questão.

Em segundo lugar é oportuno que se deixe claro a base e, por assim dizer, o pressuposto que impulsionou e tornou propício o terreno para que fosse cultivado o pensamento livre ${ }^{2}$ como afirma Pierre Clastres. Que elemento ou que elementos são esses? Ora, a Europa da época de La Boétie, século XVI, estava em plenas atividades de navegações e de chegada em territórios habitados pelos povos ameríndios, habitantes das Américas. Isso significa dizer que o contato dos europeus com esses povos trouxe à tona as mais diversas diferenças de vida possíveis.

Dentre todas as possibilidades de distinção de cotidiano, de costume, de alimentação, de vestimenta, de credo, uma é de grande relevo para a reflexão que surge naquele contexto e

\footnotetext{
${ }^{1}$ Graduando em Filosofia pela Universidade Federal do Ceará (UFC). Bolsista de Iniciação Científica pela UFC (PIBIC-UFC). E-mail: faffeijao@gmail.com.

${ }^{2}$ CLASTRES, Pierre. Liberdade, Mau Encontro, Inominável. In: Discurso da servidão voluntária, 1999 , p. 109.
} 
para o objetivo empreendido neste texto. Trata-se da não dominação daqueles povos por parte de um poder soberano enquanto modelo monárquico. Nesse sentido, o poderio soberano aqui pode ser entendido como o império de um rei e consequentemente do seu grupo de sustentação, isto é, que trabalha e que favorece a manutenção de um regime monárquico em que tudo emana do chefe maior.

É justamente esse evento histórico que condiciona o aparecimento de algo novo, de uma nova realidade, de uma nova possibilidade, de um levantamento de questão, de uma colocação em questão do que se vivia na Europa, ou na França, ou em várias nações e povos. Sim! Outro modo de vida é possível. As terras sem rei nem lei, serviram de exemplo. Obviamente que a organização entre os povos que já viviam aqui antes da chegada dos europeus não era um sistema de poder, organizado a serviço de interesses de um nome, por vezes bajulado, venerado e mantido como modelo que instaura e estabelece a verdade. É essa percepção que a visualização de um novo cenário deve ter despertado para que formulasse inquietações tão fortes e - por que não dizer? - tão poderosas.

Entretanto, só podem ser consideradas poderosas na medida em que questionam o poderoso, o poder do soberano, legalmente institucionalizado e constituído socialmente como tal. Se esse poderio coloca todos os que o obedecem em condição de subordinação deplorável, como era o caso da época, então descambar num debate dessa situação, é algo digno de ser apreciado como poderoso.

\section{Dominação e subjugação: como é possível?}

No início do Discurso, La Boétie coloca uma pergunta fundamental:

como é possível que tantos homens, tantas cidades, tantas nações às vezes suportem tudo de um Tirano só, que tem apenas o poderio que lhe dão, que não tem o poder de prejudicá-los senão enquanto aceitam suportá-lo, e que não poderia fazer-lhes mal algum se não preferissem, a contradizê-lo, suportar tudo dele. (LA BOÉTIE, 1999, p. 74).

Essa pergunta é de fundamental importância, porque ela guiará o percurso de indignação estratégica que será percorrido pelo então jovem pensador. Na realidade vivida, de poderio absurdo e de obediência cega, como se torna possível que um só, um único, possua tanto domínio em suas mãos? A condição para a viabilização disso se dá no fato de haver uma obediência forçada que está alicerçada na fraqueza dos homens. É na obediência que a procedência de um regime governamental inflamado de si, poderá produzir feitos que refletem exatamente seu modelo estrito e ditador do que deve ser cumprido. 
Coisa realmente surpreendente (e, no entanto tão comum que se deve mais gemer por ela do que surpreender-se) é ver milhões e milhões de homens miseravelmente subjugados e, de cabeça baixa, submissos a um jugo deplorável; não que a ele sejam obrigados por força maior, mas porque são fascinados e, por assim dizer, enfeitiçados apenas pelo nome de um que não deveriam temer, pois ele é só, nem amar, pois é desumano e cruel para com todos eles. (LA BOÉTIE, 1999, p. 74).

O espanto é precisamente no fato de haver uma disposição para servir, para a servidão. O mau encontro, bem acentuado por Pierre Clastres, é definido como um "acidente trágico, azar inaugural cujos efeitos não cessam de ampliar-se, a tal ponto que é abolida a memória do antes, a tal ponto que o amor da servidão substitui-se ao desejo de liberdade" (CLASTRES, 1999, p. 110).

Algumas observações são pertinentes estando explicitada a noção de mau encontro. Encontro supõe encontrar algo ou alguma coisa. Para Clastres, a abolição da lembrança do antes colabora para o diagnóstico. Antes supõe antecedência, uma passagem, nesse caso, da liberdade à servidão.

O que isso significa? Ora, há ainda que timidamente no Discurso (se concebido do ponto de vista do florescimento da antropologia nos séculos seguintes), uma reflexão antropológica, porque o sujeito de liberdade é o homem: “o enigmático mau encontro no qual se origina a História desnaturou o homem, instituindo na sociedade uma tal divisão que dela foi banida a liberdade, no entanto consubstancial ao ser primeiro do homem" (CLASTRES, 1999, p. 111). La Boétie atesta "que a liberdade é natural e que, em meu entender, não só nascemos com nossa liberdade como também com a vontade de defendê-la" (LA BOÉTIE, 1999, p. 81). Que isso quer dizer? Ora, que o estado livre que constitui essencialmente a natureza humana é propriamente o que estabelece o seu ser primeiro.

Uma ontologia do homem, uma antropologia filosófica, investiga justamente o ser do homem, e aqui precisamente a preocupação está no encontro entre a servidão e seu prevalecimento e o esquecimento da dimensão de liberdade. Essa liberdade deve ser entendida como uma indisposição, como uma recusa a servir. Tudo o que aqui se trata referente a serviço diz respeito ao soberano. Consequentemente, não se curvar diante de um autoritarismo que se proclama como digno de vênia remonta a condição do ser primeiro do homem, que “por natureza é um ser para-a-liberdade” (CLASTRES, 1999, p. 114).

A colocação, pois empregada no Discurso é uma questão que se pergunta pela natureza humana. Essa servidão explicitamente presente no comportamento do ser humano é algo inato ou é algo adquirido?

Importa saber que La Boétie trata dos animais para evidenciar a condição servil na qual se encontram os homens. 
Os bichos (valha-me Deus!), se os homens quiserem compreendê-los, gritam-lhes: Viva a liberdade! Vários deles morrem logo que são capturados. Como o peixe, que perde a vida quando o retiram da água [...]. Outros, dos maiores aos menorzinhos, quando são capturados, resistem tanto com as unhas, os chifres, os pés e o bico que por aí demonstram bastante seu apreço ao bem que lhes roubam. (LA BOÉTIE, 1999, p. 81).

Que bem é esse que é roubado no aprisionamento dos animais? É a liberdade. "Os próprios bois gemem sob o jugo, e os pássaros choram na gaiola" (LA BOÉTIE, 1999, p. 82). Isso significa dizer que todo ser que se torna consciente de sua existência, ao sentir a desgraça da sujeição procura a liberdade de modo que explicita uma vontade contrária, numa palavra: resistência. Essa noção de resistência vai ao encontro do que La Boétie chama de "vício". O vício de que o jovem pensador fala é um vício infeliz capaz de desnaturar o homem, ser que nasceu para a liberdade, ao ponto de impossibilitar-lhe uma recordação da condição primeira e não tornar viável o desejo de voltar a tal condição.

Nesse sentido, se os animais demonstram resistência, por que os homens não demonstram? Mais tarde, a ideia de superioridade do homem em relação aos animais entrará na cena antropológica. No entanto, visualizando por essa ótica, se o privilegiado da situação é o homem, por que então ele não resiste? O vício infeliz parece não favorecer a desobediência entendida como resistência ao ato de sujeição.

Voltando para o tema dos povos, das sociedades primitivas, Pierre Clastres observa bem o funcionamento de recusa à obediência, base da organização de sociedades que não possuíam Estado, não por incapacidade, mas simplesmente pela recusa da instauração institucional estatal:

O Estado pode desabar, multiplicar-se aqui em domínios feudais, dividir-se alhures em chefias locais, mas jamais é abolida a relação de poder, jamais é reabsorvida a divisão essencial da sociedade, jamais se realiza o retorno do momento pré-estatal. (CLASTRES, 1999, p. 116).

A divisão da sociedade de que se fala se refere à relação de "mando-obediência", designada, desse modo, como constitutivo primordial da manutenção da máquina de poder vigente. Noutros termos: uma vez estabelecido o Estado, parece ser impossível de um retorno ao momento anterior de sua fundação, pelo contrário, o que se pode assistir é uma germinação e enraizamento cada vez maior do poder.

Faz bem ressaltar que o intento empreendido aqui não busca contemplar uma reflexão que se pretenda estritamente sobre a questão do Estado, pois essa problemática figura apenas como elemento na constituição da possibilidade de desobediência civil.

Como desobedecer? É preciso enfrentar diretamente o poder do soberano? La Boétie responde: 
Mas o que faz com que, em toda parte e todos os dias, um homem só oprima cem mil cidades e as prive de sua liberdade? [...] E, no entanto, não é preciso combater esse tirano, só, nem mesmo dele defender-se: ele se anula por si mesmo, desde que o país não consinta a servidão. (LA BOÉTIE, 1999, p. 77).

\section{Poder de todos, poder de $U m$}

O Contra Um, subtítulo da publicação original do Discurso, explicita a indignação que se ensejava empreender a estrutura política e governamental daquele momento. No entanto, se o texto foi escrito para a Europa do século XVI, para o mundo de hoje continua bastante aplicável. "Como é que os homens perseveram em seu ser desnaturado, como a desigualdade se reproduz constantemente, como o mau encontro se perpetua a ponto de parecer eterno?". (CLASTRES, 1999, p. 114).

A interrogação acima se pergunta pelo como do poder, ou seja, como a negação da essência humana, que é a liberdade, se torna ocorrência normal e passa a se ampliar. A aparência de eternidade é evidente e se encontra no fato de, com as devidas mudanças, ainda que em regime democrático, predominar uma atualização da forma de dominação.

Depois de ter tratado de como se dá a possibilidade de dominação e subjugação de todos por parte de um, torna-se mais adequada agora a exposição de um elemento sem o qual também não seria possível a situação de rendição. Esse elemento, lembrado por Saul Newman, é o seguinte: “A lição fundamental é que o poder não depende da coerção, mas, na realidade, se apoia no nosso poder. É o nosso consentimento ativo ao poder que constitui, ao mesmo tempo, esse poder". (NEWMAN, 2011, p. 24).

Daí porque a chamada servidão voluntária é gerada por todo o povo que iludido e encantado com o que se proclama dominador, deposita nas mãos dele mesmo, por assim dizer, uma parte de poder; a reunião de inúmeras dessas partes forma um poder grandioso e forte que nesse caso se voltará contra os próprios detentores primeiros.

Como já foi demonstrado com Pierre Clastres, para La Boétie, não é natural que o homem seja sujeitado ao poder absoluto. Ora, se em Hobbes os súditos não podem se livrar da sujeição soberana, em La Boétie deve sim haver certa resistência.

O Direito de ser titular da Pessoa dos outros é entregue ao Soberano apenas pelo Pacto de uns com os outros, e não pelo Pacto do Soberano com cada uma das pessoas; então, por esse motivo, não existe qualquer violação do Pacto por parte do Soberano; e consequentemente nenhum de seus Súditos, por qualquer alegação de transgressão, pode se livrar de sua Sujeição. (HOBBES, 2015, p. 160).

O exemplo de Hobbes aqui serve apenas em nível de comparação e vale dizer que o seu pensamento que surge um século depois do de La Boétie é exatamente oposto no quesito 
do problema da servidão voluntária. O jovem pensador consegue antes mesmo de Hobbes, inaugurar a inversão de toda uma tradição teórica política que tem alicerce e base na afirmação da legitimação da soberania.

Em Hobbes, o contrato social é celebrado segundo ele, devido a circunstâncias sociais que colaboraram para tal feito. Esse contrato, legitima justamente o poder do grande Leviatã. Aqui poder e medo caminham juntos e de mãos dadas, uma vez que um complementa o outro enquanto condicionamento que garante o cumprimento efetivo do pacto: "Só o poder coercitivo do Estado, poder terrível, capaz de infundir um terror maior do que aquele produzido pelos outros homens pode servir efetivamente de garantia ao cumprimento dos pactos". (FARIA, 2007, p. 104).

O estado de natureza do homem é considerado nessa perspectiva um estágio primitivo, pré-político, a partir do qual mediante um pacto, emerge a sociedade civil. No estado natural estão estabelecidas leis naturais que não satisfazem um poder que obriga todos a obediência. O poder é uma necessidade: "A partir disso, torna-se claro que, enquanto os homens viverem sem um Poder comum para mantê-los todos intimidados, eles viverão nesse estado que é chamado de Guerra". (HOBBES, 2015, p. 117).

No entanto, o mau encontro, como já citado no ponto 1 , colocou o homem na situação de obrigação e de cumprimento do que ordena o poder. Seria esse mau encontro a chegada do homem à necessidade de proclamação de um poder? Ou ainda a impossibilidade do homem em seu estado anterior, natural, no qual está a liberdade como evidenciado, promover o estabelecimento de um modo diferente de política que não seja a celebração da soberania? Desse modo, pode-se visualizar timidamente, assim como a partir do viés antropológico, no pensamento de La Boétie, uma educação para a liberdade. Essa educação se encontra na defesa de existir, na condição do poder de $u m$, subjugação e dominação por parte justamente do que reina e impera. A educação para a liberdade é uma educação que inspira, pois, uma desobediência civil. La Boétie encerra seu Discurso com a esperança de um aprendizado:

Aprendamos pois, enfim, aprendamos a fazer o bem. Levantemos os olhos para o céu e para nossa honra, para o próprio amor da virtude, dirijamo-nos a Deus todopoderoso, testemunha de todos os nossos atos e juiz de nossas faltas. De minha parte, creio - e acredito não estar enganado - que ele sem dúvida reserva para os tiranos e seus cúmplices um castigo terrível no fundo do inferno, pois nada é mais contrário a Deus, soberanamente justo e bom, que a tirania (LA BOÉTIE, 1999, p. 108). 


\section{Democracia moderna: servidão voluntária}

Saul Newman investiga a democracia moderna como um exemplar de servidão voluntária de massa. Diante das reflexões inquietas e revoltadas de La Boétie, qual é a proposta oferecida para uma pretensa mudança de cenário?

La Boétie afirma a ideia de uma república livre. No entanto, indica que o inverso da servidão voluntária não seja a república livre, mas uma forma completamente diferente de política. As repúblicas livres têm sua própria forma de dominação, não apenas em suas leis, mas nas regras das classes ricas e proprietárias sobre as pobres. (NEWMAN, 2011, p. 27).

É nessa linha de percepção que o modelo democrático pode ser considerado como uma servidão voluntária, pois a ilusão de representatividade popular desenvolvida pelas elites e a geração de uma passividade gritante favorecem o terreno para o cultivo de uma aptidão à submissão, o que torna fértil as velhas e viciadas práticas conhecidas no mundo político contemporâneo.

É oportuno expor diante da consideração de forma diferente de política que o objetivo deste texto é simplesmente afirmar e explicitar, por assim dizer, a necessidade de uma condição diferente de política. O Discurso que aqui foi trabalhado, se torna atual e atemporal, ao ponto de no momento hodierno, continuar válido e necessário.

\section{Considerações finais}

O texto do Discurso expõe a estratégia de indignação do jovem pensador La Boétie. É estratégico porque aos poucos ele conduz o leitor para que se torne consciente da condição miserável na qual se encontra enquanto submisso e passivo a um poder soberano, ao mesmo tempo em que importa saber como demonstrado que o poder do subjugado transmite o poder do $u m$.

A indignação é evidenciada na exposição da triste situação na qual estão os homens, ou seja, na disposição em servir e em obedecer ao poder. Desse modo, a pergunta pelo como desse poder aparece como questionamento fundamental que coloca em jogo todo o edifício construído pela cristalização da soberania. Essa interrogação conduziu o jovem pensador a inauguração de uma questão antropológica, ao perguntar pela disposição do homem. Uma breve explanação do pensamento político posterior a La Boétie, mostrou rapidamente como ele conseguiu se diferenciar antes mesmo da ulterior tradição teórica política do contratualismo.

Enfim, uma tímida atualização esboçada desse pensamento permite que se observe a presença continuada de uma servidão voluntária nos moldes da forma política de democracia 
vivida nos dias de hoje. Um breve olhar sobre o Brasil atual fornece tal concepção. A forma de política de representatividade desgastada, a corrupção gritante na vida dos que possuem o poder de governabilidade nas mãos, e a mediocridade instaurada e mantida no modo de gerir a coisa pública, denotam uma conjuntura de elementos que colaboram para que o estabelecimento de uma servidão incessante, agora estruturada pelo belo discurso de uma sociedade democrática de direitos que consequentemente não são efetivados, permaneça mantido e se perpetuando.

\section{REFERÊNCIAS BIBLIOGRÁFICAS}

FARIA, Maria do Carmo Bettencourt de. Direito e ética: Aristóteles, Hobbes, Kant. São Paulo: Paulus, 2007.

HOBBES, Thomas. Leviatã ou Matéria, forma e poder de um Estado eclesiástico e civil. São Paulo: Edipro, 2015.

LA BOÉTIE, Étienne. Discurso da servidão voluntária. Comentários de Pierre Clastres. São Paulo: Brasiliense, 1999.

NEWMAN, Saul. A servidão voluntária revisitada: a política radical e o problema da autodominação. Verve. Revista Semestral Autogestionária do Nu-Sol, 20, 2011. 